\title{
Joshua D. Angrist and Jörn-Steffen Pischke: Mastering metrics
}

\author{
Princeton University Press, 2015, 282 pp., \$35, ISBN \\ 978-0-691-15284-4
}

\author{
Walter Krämer ${ }^{1}$
}

Published online: 8 May 2015

(C) Springer-Verlag Berlin Heidelberg 2015

This is a microeconometrics textbook quite out of the ordinary. First, it tackles problems starting strictly from applications, using everyday language and putting the major obstacle which has been facing modern microeconometrics in the forefront quite at the beginning: the fact that there are almost no controlled experiments, which in an ideal world would allow for simple causal inference, and what to do about it. Second, it mentions technical problems and formula only in passing, if at all. My favorite is the definition of mathematical expectation on page 14: "The mathematical expectation of a Variable, $\mathrm{Y}_{\mathrm{i}}$, written $\mathrm{E}\left(\mathrm{Y}_{\mathrm{i}}\right)$, is the population average of this variable." While more mathematically inclined readers will wince at this, this approach will certainly help economists not familiar with mathematical statistics to still capture some of the basic techniques and ideas.

The book is obviously written for an Anglo-Saxon audience and addresses problems which are mostly of interest to students from this cultural environment: whether it pays in later earnings to accept a costly offer from Harvard rather than attend a heavily subsidized minor State University, whether differences in legal drinking age across American States induce different patterns of traffic accidents, or whether more money for public health insurance produces better health. If one does not mind this rather parochial point of view, there is certainly no better introduction to modern microeconometrics than this book.

\footnotetext{
Walter Krämer

walterk@statistik.tu-dortmund.de

1 TU Dortmund University, Dortmund, Germany
} 